\title{
Size and clustering of ethnic groups and rates of psychiatric admission in England
}

\author{
Gayathri Venkatesan, ${ }^{1}$ Scott Weich, ${ }^{2}$ Orla McBride, ${ }^{3}$ Liz Twigg, ${ }^{4}$ Helen Parsons, ${ }^{2}$ Jan Scott, ${ }^{5}$ \\ Kamaldeep Bhui, ${ }^{6}$ Patrick Keown ${ }^{5}$
}

BJPsych Bulletin (2018) 42, 141-145, doi:10.1192/bjb.2018.17

${ }^{1}$ Tranwell Unit, Gateshead; ${ }^{2}$ University of
Warwick, Coventry; ${ }^{3}$ University of
Ulster, County Londonderry, Ulster;
${ }^{4}$ University of Portsmouth, Portsmouth;
${ }^{5}$ Newcastle University, Newcastle;
${ }^{6}$ Queen Mary University of London,
London

Correspondence to Gayathri Venkatesan (Gayathri.venkatesan@ntw.nhs.uk)

First received 13 Sep 2017, final revision 16 Jan 2018, accepted 19 Feb 2018

(c) The Authors 2018. This is an Open Access article, distributed under the terms of the Creative Commons

Attribution-NonCommercial-

NoDerivatives licence (http:// creativecommons.org/licenses/by-ncnd/4.0/), which permits noncommercial re-use, distribution, and reproduction in any medium, provided the original work is unaltered and is properly cited. The written permission of Cambridge University Press must be obtained for commercial re-use or in order to create a derivative work.
Aims and method To compare rates of admission for different types of severe mental illness between ethnic groups, and to test the hypothesis that larger and more clustered ethnic groups will have lower admission rates. This was a descriptive study of routinely collected data from the National Health Service in England.

Results There was an eightfold difference in admission rates between ethnic groups for schizophreniform and mania admissions, and a fivefold variation in depression admissions. On average, Black and minority ethnic (BME) groups had higher rates of admission for schizophreniform and mania admissions but not for depression. This increased rate was greatest in the teenage years and early adulthood. Larger ethnic group size was associated with lower admission rates. However, greater clustering was associated with higher admission rates.

Clinical implications Our findings support the hypothesis that larger ethnic groups have lower rates of admission. This was a between-group comparison rather than within each group. Our findings do not support the hypothesis that more clustered groups have lower rates of admission. In fact, they suggest the opposite: groups with low clustering had lower admission rates. The BME population in the UK is increasing in size and becoming less clustered. Our results suggest that both of these factors should ameliorate the overrepresentation of BME groups among psychiatric inpatients. However, this overrepresentation continues, and our results suggest a possible explanation, namely, changes in the delivery of mental health services, particularly the marked reduction in admissions for depression.

Declaration of interest None.
It has been known for some time that Black and minority ethnic (BME) groups are overrepresented among psychiatric in-patients in the National Health Service (NHS). ${ }^{1}$ The Count Me In census confirmed that this overrepresentation persists and may be becoming more pronounced. ${ }^{2}$ The census also consistently demonstrated significant variation between BME groups, with most having higher rates of admission but some having lower rates compared with the national average. These differences in admission rates are likely to be explained by three main factors: differences in the incidence and rates of mental disorder; service-related factors, such as pathways into in-patient care; and changes in the size and distribution of the ethnic minority groups in the UK. ${ }^{1,3-5}$

\section{Background}

One of the earliest demonstrations of the ethnic density hypothesis was the study of psychiatric admission rates in Chicago by Faris and Dunham. ${ }^{6}$ Several subsequent studies have supported this idea of a 'protective' ethnic density effect, whereby individuals living in areas with a greater proportion of people of the same ethnicity have better health. ${ }^{7-10}$ However, not all studies have consistently found results that support the ethnic density hypothesis. ${ }^{11} \mathrm{~A}$ study at a wider regional scale in England failed to show any effect within individual ethnic groups, although there was some evidence to support differences between ethnic groups. $^{12}$

In response, Halpern argued that within-group ethnic density operates at a local level, for example, by reducing levels of ethnic discrimination and increasing levels of social support, and may not be detected when the scale of investigation is at a regional or national level. ${ }^{13}$ Halpern made two predictions about between-group effects that might be evident at a larger scale: (a) smaller ethnic groups will tend to have higher psychiatric admission rates than larger groups, and (b) groups that have a stronger tendency to cluster together will tend to have lower admission rates. We aimed to empirically test these two predictions at a national level in England by linking NHS mental health admission rate data from 2005/06 to UK census ethnic group 
population estimates, and examining national level mental health admission rates for each BME group according to the population size of each group and the degree of clustering of each group across England.

\section{Method}

Rates of admission were calculated for the 16 ethnic groups as used in the UK census, while controlling for age and symptom type.

\section{Population}

The population size of each ethnic group was obtained from the 'Understanding Population Trends and Processes' section of the Ethnic Group Population Projection (ETHPOP) database. This is a web resource maintained by the University of Leeds, which provides projections of each ethnic group at various levels, including the national level. ${ }^{14}$

The index of dissimilarity was used as a measure of clustering for each ethnic group. ${ }^{15}$ This ranges from 0 (indicating full integration) to 100 (indicating full segregation). An index of less than 40 indicates low levels of segregation, while one of 40 or more indicates moderate to high levels of segregation. ${ }^{16}$ Data were obtained from the Centre on Dynamics of Ethnicity website. ${ }^{17}$

\section{Number of admissions and symptom type}

Routine clinical data were used. The numbers of in-patient episodes in the NHS (finished consultant episodes) in 2005/06 were obtained for three broad diagnostic groups: schizophreniform (schizophrenia and related disorders), mania (manic episodes) and depression (unipolar and bipolar depressive episodes).

\section{Age at admission}

Five age bands were created: 10-19, 20-29, 30-39, 40-49 and 50-59 years. The age range was restricted to 10-59 years for two reasons. First, there are far fewer admissions for these diagnostic groups prior to the teenage years. Second, beyond 60 years of age, the population size of several ethnic groups is so small, even at the national level, that there are too few admissions for the calculation of meaningful rates to be possible.

\section{Rates}

Rates of admission were calculated per 100000 population for each ethnic group. Age standardisation was used to compare the 16 groups by assuming each group had the same population as the European standard.

\section{Relative rates}

The average rate of admission for BME groups was compared with the White British group to calculate relative rates for each of the 10-year age bands.

\section{Outlier}

One group (other Black) had rates that were consistently outside the spread of the other groups. Subsequent years of the Count Me In census showed that this was the one group that decreased in size as self-recording of ethnicity improved instead of staff recording of ethnicity. An adjustment was made by distributing the excess admissions among four other groups (Black Caribbean, Black African, mixed White and Black Caribbean, and mixed White and Black African).

\section{Results}

\section{Rates of admissions}

The average (s.d., range) age standardised rates of admission per 100000 were 139.3 (89.9, 46.7-335.0) for schizophreniform disorders, 30.0 (16.3, 6.6-53.5) for mania and 66.9 (23.9, 21.9-106.6) for depression. There was an eightfold difference in rates of schizophreniform and mania admissions, and a fivefold difference in the rate of depression admissions, between ethnic groups. The rate of admission in the White British group was within the range for all three types of admission, albeit at the lower end of the range for schizophreniform (59.3) and mania admissions (14.3), and the middle of the range for depression (63.7).

\section{Relative rate of admission}

In each of the 10 year age bands, the average relative rate of admission for BME groups was higher than that of the White British group for schizophreniform and mania admissions, but not for depression. These differences were most pronounced in younger age bands and tended to decrease with age. The relative rate of admission for mania dropped the most, from 3.5 (1.6-5.4) to $1.7(1.2-2.3)$. The relative rate of admission for schizophreniform disorders dropped from 2.9 (2.0-4.0) to 2.3 (1.6-3.1). In depression, the relative rate was $1.5(0.9-2.2)$ in those aged 10-19 years and 1.1 (0.8-1.3) in those aged 50-59 years (Fig. 1).

\section{Association of rate of admission with group size and clustering}

The mean (s.d.) index of dissimilarity score for the 16 ethnic groups (including White British) was $46 \%$ (13) with a range of $27-67 \%$. The average population size for those aged 10-59 years was $2116 \mathrm{k}$ with a range of $65 \mathrm{k}$ to $28170 \mathrm{k}$. There was a moderate positive rank correlation between the index of dissimilarity score and rates of admission for schizophreniform disorders, and a weak correlation with rates of admission for mania, and no correlation with rates of admission for depression. By contrast, there was a weak or moderate negative rank correlation between the size of each of the 16 ethnic groups and the corresponding age-standardised rate of each category of admission (Table 1).

Ethnic groups with populations aged between 10 and 59 years that were larger than half a million had relatively low rates of admission. Smaller ethnic groups with low levels of clustering ( $<40 \%$ index of dissimilarity) also tended to have 
Fig. 1 Average relative rates (with confidence intervals) of admissions for BME groups compared with the White shown separately for schizophreniform (red), mania (blue) and depression (black) admissions. Data are for England 2005/6. British group. Data are

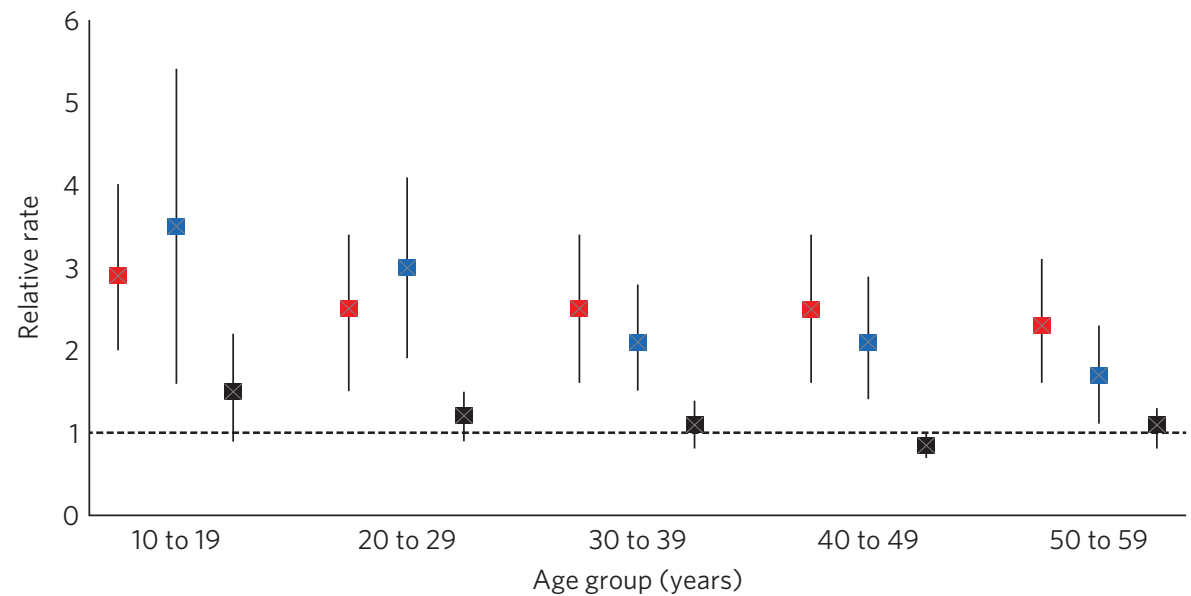

lower rates of admission. Smaller ethnic groups with high levels of clustering (>40\% index of dissimilarity) had higher rates of admission.

This pattern was most evident in schizophreniform admissions, where rates were on average three times higher in small clustered groups than the rates in groups with a larger population size. The rates of admission for mania were twice as high in smaller ethnic groups with high levels of clustering when compared with rates of admission for mania in ethnic groups with a larger population. The increase was least evident in depression admissions, where rates were about $40 \%$ higher in small clustered groups than the rates in groups with a larger population size (Table 2).

\section{Discussion}

In line with previous studies, our results demonstrate an increased rate of admission in the majority of BME groups. There was significant variation in admission rates between ethnic groups, and there appeared to be an interaction with age. According to our results, the greatest increase in admission rates was in teenagers and young adults. By contrast, the AESOP study indicated that the incidence of psychosis remains raised in ethnic minority groups throughout the age range of our study. ${ }^{18}$ This may indicate a reduced

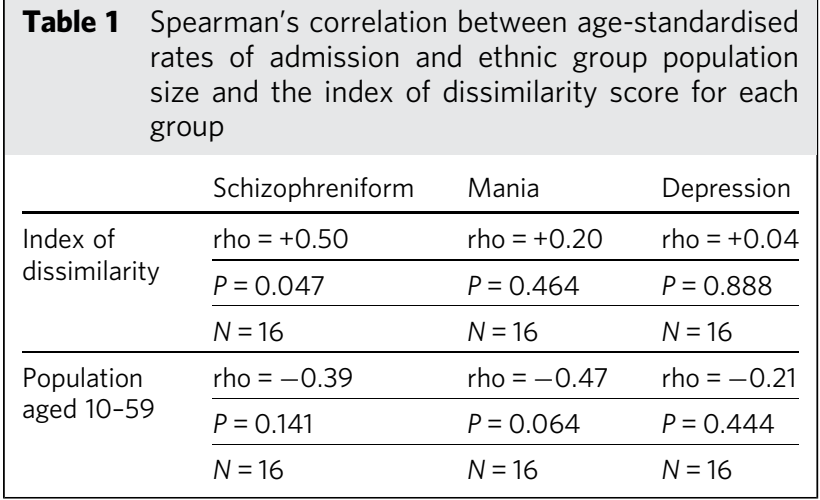

The data are for 16 ethnic groups in England. risk of (re)admission with increasing age in BME groups relative to the White British population.

Our findings provide support for the hypothesis that larger ethnic groups have lower rates of admission. This is a between-group effect rather than a within-group effect. In this study, located in England, which has a population aged 10-59 years of 40 million, ethnic groups with populations over half a million had lower rates of admission. Our findings do not support the hypothesis the more clustered groups have lower rates of admission. In fact, they suggest the opposite: groups with low clustering had lower admission rates. Again, it is important to emphasise that this study only looked at between-group effects and did not investigate within-group effects.

The BME population in the UK is increasing in size and becoming less clustered. ${ }^{16}$ Our results suggest that both of these factors should ameliorate the overrepresentation of BME groups among psychiatric in-patients. However, the Count Me In census indicated that this overrepresentation continues. The answer may lie in changes in the delivery to mental health services. We have previously shown that that although rates of admission have fallen across England, one of the largest reductions has been in admissions for depression, whereas admissions for schizophrenia and mania have shown only a modest, if any, reduction. ${ }^{19}$

In this work, we have shown that the increased rate of admission for BME groups was confined to schizophreniform disorders and mania, but was not found in depression. Therefore, all other things being equal, reducing the rate of admissions for depression alone will have the unintended consequence of increasing the overrepresentation of BME groups in the psychiatric in-patient population. The same applies to interventions that are more effective in reducing admissions in adults over 35 years of age than in younger adults, such as crisis resolution home-based treatment (http://www.ethpop.org).

\section{Limitations}

Gender-specific data were not available; hence, standardisation by gender was not possible. The diagnostic information was from routine clinical practice. For the majority of patients, ethnicity was self-determined, but for a minority 


\begin{tabular}{|c|c|c|c|c|}
\hline \multirow[b]{3}{*}{ No. ethnic groups } & \multirow{3}{*}{$\begin{array}{l}\text { Population }>500000 \text { aged } 10-59 \\
\qquad N=4\end{array}$} & \multirow{2}{*}{\multicolumn{2}{|c|}{$\frac{\text { Population }<500000 \text { aged } 10-59}{\text { Index of dissimilarity }}$}} & \multirow[t]{3}{*}{ ANOVA } \\
\hline & & & & \\
\hline & & $\begin{array}{l}<40 \% \\
N=4\end{array}$ & $\begin{array}{l}>40 \% \\
N=8\end{array}$ & \\
\hline Schizophreniform & 71.6 & 73.0 & 206.4 & $F=9.51$ \\
\hline $95 \% \mathrm{Cl}$ & $38.2,105.0$ & $7.1,138.8$ & $141.1,271.7$ & $P=0.003$ \\
\hline Mania & 17.9 & 19.3 & 41.3 & $F=6.98$ \\
\hline $95 \% \mathrm{Cl}$ & $8.0,27.7$ & $-4.1,42.3$ & $30.6,52.1$ & $P=0.009$ \\
\hline Depression & 56.9 & 50.8 & 80.0 & $F=3.16$ \\
\hline $95 \% \mathrm{Cl}$ & $21.9,92.0$ & $0.0,101.6$ & $68.8,91.1$ & $P=0.076$ \\
\hline
\end{tabular}

of patients the ethnicity category would have been picked by staff.

It is impossible to avoid the ecological fallacy when analysing population level data. This ecological study was undertaken at a national level and, therefore, the results may be affected by the ecological fallacy (i.e. associative results observed at this national level are not necessarily replicated at the individual or smaller geographical levels. ${ }^{20}$ However, the finding of an association between ethnic groups and higher rates of detention is fully consistent with a number of studies that have found higher rates of psychosis and admission among individuals from BME groups.

Local area of residence is likely to reflect aspects of group membership dynamics, such as local ethnic density, dissimilarity and sense of membership. These are likely to be more fluid than individual-level variables. We argue that ethnicity may operate at various levels, including those of the individual, local area, region, and nation, and perhaps even beyond national boundaries; however, our national-level data did not allow us to investigate these nuances.

This study included information on the number of admissions in England for each ethnic group. It did not have access to any individual-level data or local area data. A further study is required with a more detailed data-set, including detention outcomes recorded at individual, local area, regional and national levels, and corresponding explanatory variables as in our previous study. ${ }^{21}$ Dual diagnoses, specific substance use and multiple admissions should all be considered in future studies.

\section{Clinical implications}

If these associations are replicated, then this study has several implications. The first is that as ethnic groups increase in size and become more evenly spread, relative rates of admission will fall.

Second, any change in the pattern of admission, according to broad diagnostic group, symptom type or age, is likely to affect the ethnic make-up of the psychiatric in-patient population. For example, home-based treatment as an alternative to admission has been shown to be more effective for depression and for adults over the age of 35. An indirect consequence of this could be an exacerbation of the overrepresentation of $\mathrm{BME}$ groups among the remaining in-patient population.

Future research in this area will model the effects that population change and changes in psychiatric practice since $2005 / 6$ have had on the psychiatric in-patient population over the subsequent decade.

\section{About the authors}

Gayathri Venkatesan is a Consultant Neuropsychiatrist at Walkergate Park Newcastle, UK; Scott Weich is a Professor of Mental Health at the Division of Mental Health and Wellbeing, Warwick Medical School, University of Warwick, Coventry, UK; Orla McBride is a Lecturer in Psychology at the School of Psychology, University of Ulster, County Londonderry, Ulster, UK; Liz Twigg is a Professor of Human Geography at the Department of Geography, University of Portsmouth, Buckingham Building, Portsmouth, UK; Helen Parsons is a Senior Research Fellow at the Division of Health Sciences, Warwick Medical School, University of Warwick, Coventry, UK; Jan Scott and Patrick Keown are Consultant Psychiatrists at Newcastle University, Academic Psychiatry, Campus for Ageing \& Vitality, Newcastle, UK; and Kamaldeep Bhui is a Professor of Cultural Psychiatry and Epidemiology at the Centre for Psychiatry, Barts and The London School of Medicine and Dentistry, Queen Mary University of London, UK.

\section{References}

1 Bhui K, Stansfeld S, Hull S, Priebe S, Mole F, Feder G. Ethnic variations in pathways to and use of specialist mental health services in the UK. $\mathrm{Br} J$ Psychiatry 2003; 182(2): 105-16.

2 Bhui K, Stansfeld S, McKenzie K, Karlsen S, Nazroo J, Weich S. Racial/ ethnic discrimination and common mental disorders among workers: findings from the EMPIRIC Study of Ethnic Minority Groups in the United Kingdom. Am J Public Health 2005; 95(3): 496-501.

3 Boydell J, Van Os J, McKenzie K, Allardyce J, Goel R, McCreadie RG, et al. Incidence of schizophrenia in ethnic minorities in London: ecological study into interactions with environment. Br Med J 2001; 323 (7325): 1336.

4 Cochrane R, Bal SS. Ethnic density is unrelated to incidence of schizophrenia. Br J Psychiatry 1988; 153(3): 363-6.2.

5 Care Quality Commission Count Me In 2010. CQC, 2011 (http://www. cqc.org.uk/sites/default/files/documents/count_me_in_2010_final_tagged.pdf). 
6 Das-Munshi J, Becares L, Dewey ME, Stansfeld SA, Prince MJ. Understanding the effect of ethnic density on mental health: multi-level investigation of survey data from England. Br Med J 2010; 341: c5367.

7 Duncan OD, Duncan B. A methodological analysis of segregation indexes. Am Sociol Rev 1955; 20(2): 210-7.

8 Faris REL, Dunham HW. Mental Disorders in Urban Areas: An Ecological Study of Schizophrenia and Other Psychoses. University of Chicago Press, 1939.

9 Fearon P, Kirkbride JB, Morgan C, Dazzan P, Morgan K, Lloyd T, et al. Incidence of schizophrenia and other psychoses in ethnic minority groups: results from the MRC AESOP Study. Psychol Med 2006; 36 (11): 1541-50.

10 Glover G, Arts G, Babu KS. Crisis resolution/home treatment teams and psychiatric admission rates in England. Br J Psychiatry 2006; 189 (5): 441-5.

11 Halpern D. Minorities and mental health. Soc Sci Med 1993; 36(5): 597-607.

12 Halpern D, Nazroo J. The ethnic density effect: results from a national community survey of England and Wales. Int J Soc Psychiatry 2000; 46 (1): 34-46.

13 Karlsen S, Nazroo JY, Stephenson R. Ethnicity, environment and health: putting ethnic inequalities in health in their place. Soc Sci Med 2002; 55 (9): 1647-61.
14 Keown P, Mercer G, Scott J. Retrospective analysis of hospital episode statistics, involuntary admissions under the Mental Health Act 1983, and number of psychiatric beds in England 1996-2006. Br Med J 2008; 337.

15 Morgan C, Charalambides M, Hutchinson G, Murray RM. Migration, ethnicity, and psychosis: toward a sociodevelopmental model. Schizophr Bull 2010; 36(4): 655-64.

16 Parkinson M, Champion T, Simmie J, Turok I, Crookston M, Katz B, et al State of the English Cities (vol 1-2), Office of Deputy Prime Minister, 2006.

17 Rees $\mathrm{P}$, Wohland $\mathrm{P}$, Norman $\mathrm{P}$, Boden $\mathrm{P}$. Ethnic population projections for the UK, 2001-2051. J Popul Res 2012; 29(1): 45-89.

18 Simpson L. More Segregation or More Mixing. University of Manchester: Centre on Dynamics of Ethnicity, 2012.

19 Singh SP, Greenwood NAN, White S, Churchill R. Ethnicity and the mental health act 1983. Br J Psychiatry 2007; 191(2): 99-105.

20 Robinson WS. Ecological correlations and the behavior of individuals. Am Sociol Rev 1950; 15(3): 351-7.

21 Weich S, McBride O, Twigg L, Duncan C, Keown P, Crepaz-Keay D, et al. Variation in compulsory psychiatric in-patient admission in England: a cross-classified, multilevel analysis. Lancet Psychiatry 2017; 4(8): 619-26. 